\title{
MODERNIZAÇÃO E CRESCIMENTO POPULACIONAL NOS MUNICÍPIOS DE MINAS GERAIS: UMA APLICAÇÃO DO MÉTODO “GRADE OF MEMBERSHIP"
}

\author{
Ricardo Alexandrino Garcia
}

\section{1- INTRODUÇÃO}

Segundo um dos dicionário de língua portuguesa mais consultados no país, por Modernização se entende: ato ou efeito de modernizar(-se); já o verbete modernizar significa: tornar moderno, dar feição moderna a, adaptar aos usos ou necessidades modernas; e, por fim, tem-se o verbete moderno, proveniente do latim modernu, que quer dizer: dos tempos atuais ou mais próximos de nós; recente; atual, presente, hodierno. Modernista: que está na moda; diz-se das manifestações artísticas e literárias do século XX etc. Como pode-se perceber, é grande a pluralidade de definições do verbete modernização contida no léxico português.

Na busca de uma conceituação do termo Moderno, Inkeles, Smith (1981, p. 15-35) deparam-se com a mesma problemática da multiplicidade de significados desse termo. Entretanto, explicitaram que os aspectos cabais de uma sociedade moderna inclui a educação de massa, a urbanização, a industrialização, burocratização e meios rápidos de comunicação e de transporte. Consideraram, ainda, a simultaneidade de dois processos complementares na formação dessas sociedades: a modernização econômica e a modernização política. Enquanto o primeiro diz respeito à forma de organização social, aos modos de organizar e de fazer, às instituições; o segundo atenta para a organização cultural e imaginária, para os modos de pensar e de sentir, para o indivíduo. Identificaram, assim, dois tipos de processos nas sociedades modernas, um de natureza social e política e outro de natureza social e psíquica.

Para Harvey (1989, p. 97-108), Modernização é sinônimo de processo de modernização capitalista. Tendo como base análise crítica da modernização capitalista cunhada por Karl Marx, o autor salienta o caráter intermediário das relações entre o homem e a natureza, pós a implementação da "economia do dinheiro". As relações humanas, uma vez intermediadas pelo capital, geram processo sociais que se caracterizam pela promoção de uma situação que forja a sensibilidade, princípios e práticas estéticas de pensadores e produtores culturais de modo que não reflitam nenhuma mudança fundamental da condição social. Nesse sentido, o individualismo, a alienação, a 
fragmentação, a efemeridade, a inovação, a destruição criativa, o desenvolvimento especulativo, mudanças imprevisíveis nos processos de produção e de consumo, mudança da experiência de tempo e espaço e uma dinâmica de mudança social impelida pela crise são algumas das múltiplas facetas desse processo.

Para melhor compreender o que se quer chamar por Modernização, seria útil caracterizar seus termos homólogos Modernidade e Modernismo. Para Featherstone (1995, p. 20-30), o termo Modernidade sugere, por um lado, um sentido de época; define-se, por exemplo, a idade moderna em relação à idade média ou, ainda, modernidade em relação à antigüidade; e, por outro, a terminologia sugere uma disposição de espírito ou estado da mente experimentado pelo homem moderno, a sensibilidade moderna, induzindo um sentido de descontinuidade, de rompimento, de novidade, de efemeridade e de fugacidade perante a vida. Já o vocábulo Modernismo, em seu sentido mais estrito, indica os estilos artísticos e arquitetônicos surgidos no final do século XIX e início do século XX; suas características básicas são a reflexividade, a autoconsciência estética, a exploração da natureza paradoxal, a ambiguidade, a desintegração e a simultaneidade. Assim, para o autor:

\footnotetext{
"Modernização é um termo usado habitualmente na sociologiado desenvolvimento para indicar os efeitos do desenvolvimento econômico sobre estruturas sociais e valores tradicionais. A teoria da modernização é usada ainda para designar as etapas do desenvolvimento social baseadas na industrialização, a expansão da ciência e da tecnologia, o Estado Moderno, o mercado capitalista mundial, a urbanização e outros elementos infraestruturais(...)."
}

Por fim, Inglehart (1997, p. 7-17) salienta que a Modernização é antes de tudo uma síndrome em que processos democráticos não lhe são necessariamente inerentes, também não possui um caráter etnocêntrico, não é monocausal e não possui linearidade. Um ponto crucial em sua teoria é que a industrialização articula-se com processos específicos de mudanças sociopolíticas amplamente conhecidas: embora sociedades pré-industriais variem, pode-se falar, por um lado, de um modelo de sociedade moderna ou industrial para as quais todas caminhariam, uma vez iniciado seus próprios processos de industrialização; por outro, o desenvolvimento econômico relaciona-se com um amplo aspecto de mudanças que incluem não apenas a industrialização, mas também urbanização, educação de massa, especialização ocupacional, burocratização, e desenvolvimento de meios de comunicação que, por sua vez, também se articulam com um grande conjunto de mudanças de ordem cultural, social e política. Nesse sentido, Inglehart concorda com os apontamentos de Germani (1969) que já preconizava a inexorabilidade da transição de 
sociedades tradicionais para sociedades modernas através de mudanças estruturais que desintegram as sociedades tradicionais, fazendo emergir sociedades mais modernas.

Outra razão é que os dados utilizados não fazem mais que sugerir variáveis relevantes e falham na explicação global das dinâmicas subjacentes aos modelos. Em vários exemplos, os dados são também parcimoniosos, e a informação descritiva básica, para uma ou mais narrativas, pode ser perdida.

Uma vez que as teorias demográficas enfocam aspectos semelhantes da transição demográfica e enfatizam sua explicação em modelos monocausais distintos e não multe excludentes, parece evidente que tal fenômeno é, no mínimo, multideterminado. Nesse sentido, essas teorias carecem de uma releitura a luz de uma postura mais articulada, pois se o que se objetiva é a caracterização

das leis que regeram, e que regem, a transição da fecundidade nos mais diversos contextos e épocas, é necessário que se tenha em mente os seguintes princípios:

i) as relações entre condicionantes da dinâmica demográfica, que operam na esfera macro, e as mudanças institucionais, estrutura econômica e mudanças demográficas, e trocas motivacionais;

ii) os mecanismos sócio psicológicos, que atuam em nível micro, afetam as mudanças nas preferências, o aumento da legitimidade dos instrumentos racionais, mudanças na percepção dos custos benefícios e oportunidades/restrições, e o crescimento de alternativos escritos de procedimentos;

iii) a difusão de novas preferências, percepções, legitimidade e escritos procedimentais via mecanismos de contágio ou aprendizado ou via mecanismos de mobilização e propaganda;

iv) os aspectos da inovação e difusão de habilidade (Lestheaghe, 1997, p. 15).

Chama a atenção o fato de os aspectos vinculados à dinâmica demográfica parecer possuir a mesma ideia de multicausalidade daquela exposta por Inglehart sobre Modernização. Contudo tanto o debate sobre o processo de modernização quanto o debate sobre os determinantes do crescimento populacional são permeados por profusas teorias que não podem ser apreendidas num estudo tipo cross-section. Visto isso, não se pretende aqui propor qualquer espécie de síntese dos referenciais teóricos citados ou propor, dentre os inúmeros determinantes desses processos, quais os mais relevantes. O que se quer é procurar identificar que dimensões podem ser articuladas para indicar 
distintos perfis de modernização em um dado momento através de uma investigação empírica.

O que se está objetivando, portanto, nesse estudo é classificar os municípios de Minas Gerais em relação ao seu grau de modernização e verificar sua associação com as taxas de crescimento populacional dessas áreas no período 1991-1996; para tanto, é necessário caracterizar melhor quais dimensões podem estar relacionadas a esse processo, no intuito de se buscar elementos que permitam operacionalizar, lato sensu, uma medida de modernização.

Grosso modo, pode-se dizer que em uma sociedade moderna, o homem não vive mais num meio natural e sim num meio tecnicamente construído, que interpõe uma rede de máquinas e técnicas apuradas entre o homem e a natureza. Em decorrência da expansão dos recursos técnicos, a estrutura social torna-se mais complexa do que a da sociedade tradicional.

Dentro do escopo das teorias de modernização, Inkeles e Smith explicitaram que os aspectos cabais de uma sociedade moderna inclui a educação de massa, a urbanização, a industrialização e meios rápidos de comunicação; Harvey apontou para os processos de produção e de consumo; Featherstone salientou a industrialização, a expansão da ciência e da tecnologia e a urbanização; e Inglehart, a industrialização, urbanização, educação de massa, especialização ocupacional e desenvolvimento de meios de comunicação.

A partir do exame das proposições acima verifica-se que o debate sobre modernização é permeado por duas grandes dimensões analíticas: a industrialização e a urbanização. Na primeira ressaltam-se os aspectos ligados à produção e ao consumo de bens e serviços e os vinculados à reprodução da força de trabalho; na segunda, salientam-se sua intensidade, a infra-estrutura necessária para sua implementação e o desenvolvimento das telecomunicações que lhe é inerente.

O construto apresentado no Quadro 1 indica como foi esquematizadaa investigação empírica das dimensões convergentes do processo modernização.Nele, estão representadas as duas grandes dimensões, suas principaiscomponentes e que aspectos dessas componentes podem ser investigados empiricamente, de modo que possam abranger o maior número possível de elementosabordados ${ }^{1}$ :

\footnotetext{
${ }^{1}$ Cabe ressaltar aqui que essas dimensões estão disposta separadamente apenas para fins de organização e apresentação de seus aspectos que podem ser investigados com base nas informações do Censo Demográfico de 1991.
} 


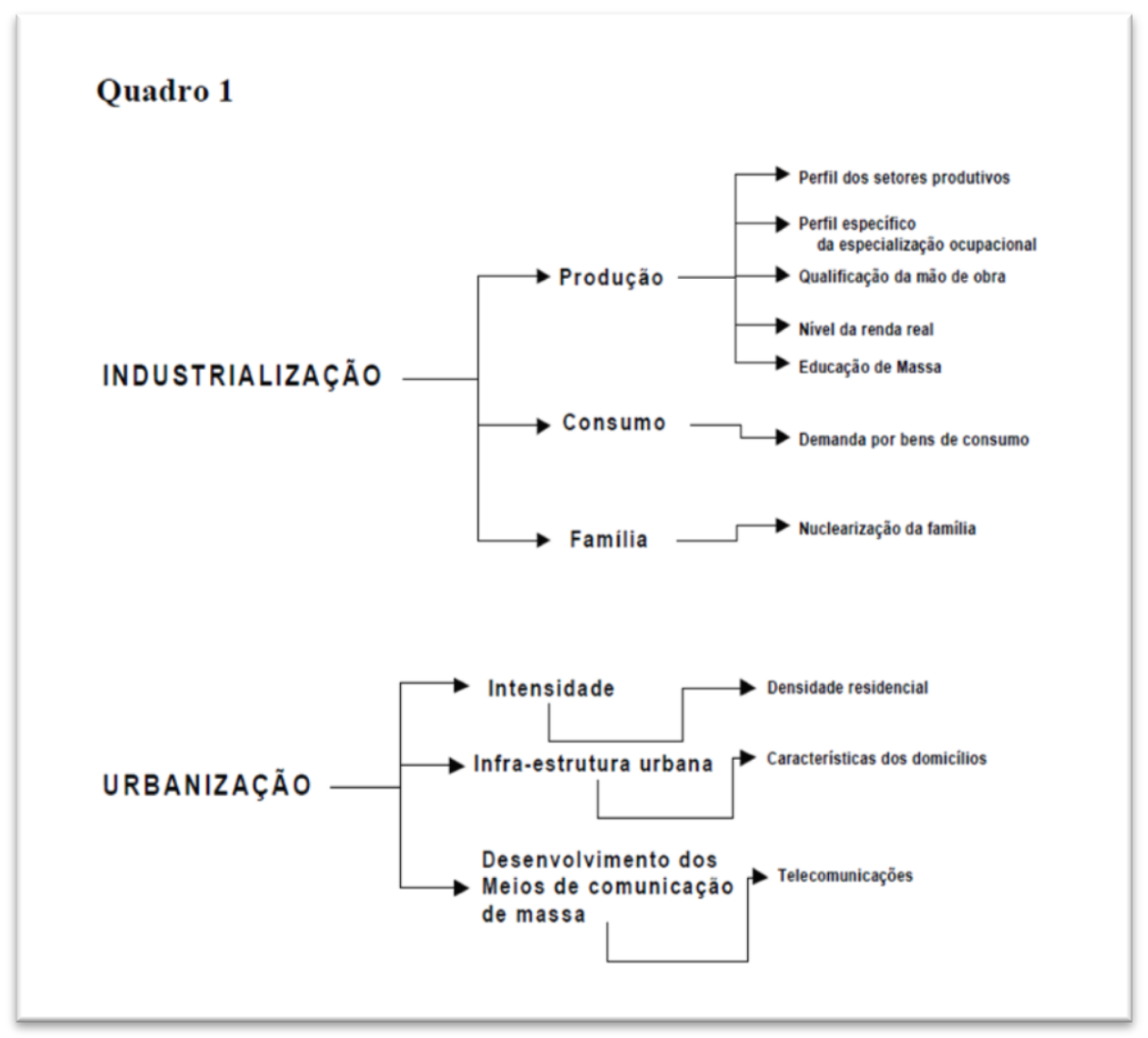

Foram arroladas, assim, duas grandes dimensões analíticas, tendo como base o que foi ilustrado pelos referenciais teóricos e as limitações impostas pela fonte de dados: a primeira diz respeito aos aspectos vinculados à industrialização e a segunda, aos vinculados à urbanização.

Tendo em vista que o que se quer é obter os perfis dos municípios de Minas Gerais no tocante ao seu grau de modernização, eles foram inicialmente caracterizadas de acordo com os percentuais de prevalência de atributos de 49 variáveis internas e 1 externa (Taxa de Crescimento Total a.a) que constituíram as componente das dimensões acima mencionadas. $\mathrm{Na}$ operacionalização

da pesquisa empírica, a disposição das variáveis obedeceu à seguinte estrutura de investigação: 
Quadro 2

(Continua)

\section{URBANIZAÇÃO}

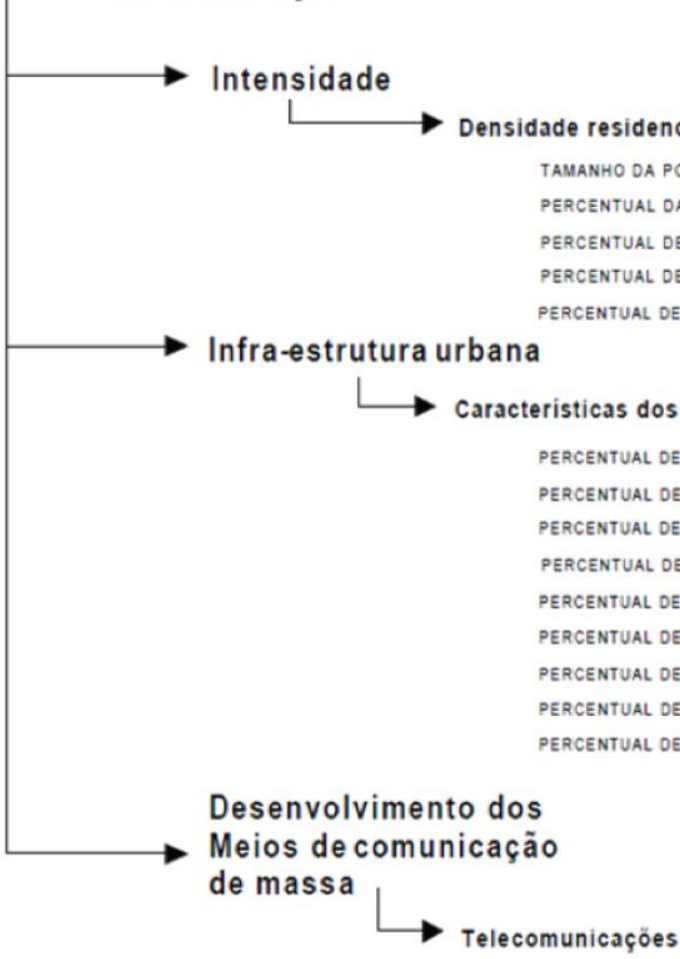

PERCENTUAL DE DOMICILIOS COM TELEFONE

PERCENTUAL DE DOMICILIOS COM RÁdO

PERCENTUAL DE DOMICILIOS COM TV

Cadernos do Leste 


\section{Quadro 2}

(Conclusão)

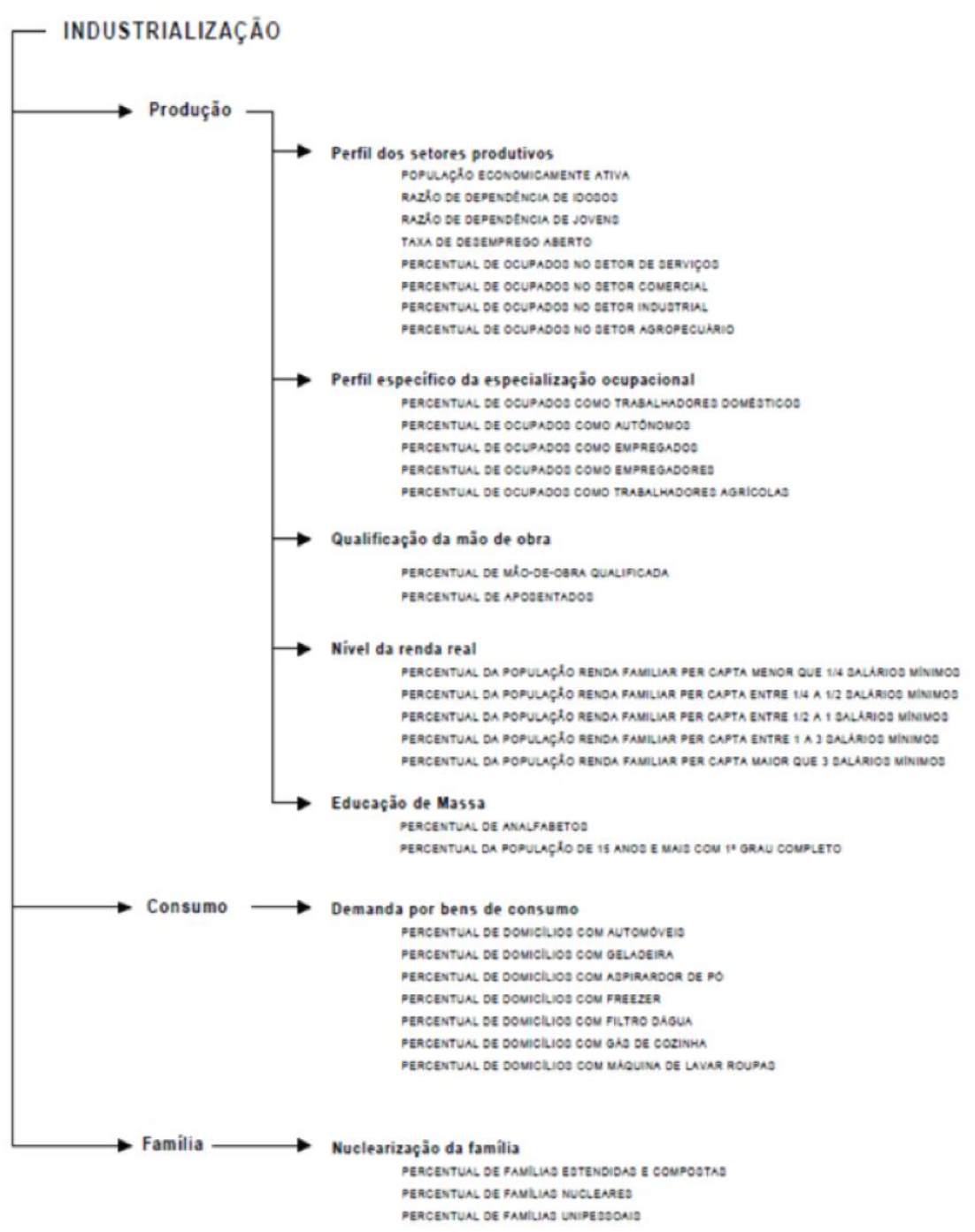

\section{2- O MÉTODO DE GOM}

Esta técnica foi desenvolvida a partir da teoria dos conjuntos nebulososde Zadeh (1965), e presta-se à modelagem multidimensional de dadosdiscretos (Manton et al., 1994) ${ }^{2}$. O método estima, com base em um modelode probabilidade multinomial, dois tipos de parâmetros: um de associação, gik,e outro de estrutura, $\square \mathbf{k j \mathbf { l }}$; ou seja, os graus de pertinência (g) de cada elemento(i) à cada subconjunto, ou perfil, ou tipo (k); e as probabilidades de cada categoria $(\square)$ de cada variável (j) em cada perfil (k) que, por sua vez,

\footnotetext{
${ }^{2}$ Como o método foi elaborado para dados discretos, optou-se por categorizar todas as variáveis selecionadas em função de seus decis.
}

Cadernos do Leste

Artigos Cientificos 
define esseperfil. Segundo Manton (1994), esse modelo de probabilidade multinomial édado por:

Equação 11

$$
L_{(y)}=\prod_{i=1}^{I} \prod_{i=1}^{J} \prod_{i=1}^{L /}\left(\Sigma g_{i k} \lambda_{k j l}\right)^{Y i j l}
$$

Onde: Yijl denota o estado binário (zero ou um) que cada elemento (i) assumiu perante a categoria (l) da variável (j), sendo que para todas as combinações de i e j, Yijl será sempre igual a zero, exceto para um e somente um 1 que será igual a unidade.

Verifica-se, então, que quando se busca, a partir de variáveis categórica, classificar elementos em perfis homogêneos e distintos, levando em consideração sua multidimensionalidade bem como o alto grau de heterogeneidade que venham apresentar. Esse modelo apresenta grandes vantagens quando se dispõe de um número elevado de variáveis e uma pequena quantidade de elementos ou observações, principalmente quando comparado a outras técnicas de análise de clustering (Machado, 1997).

\section{O método de GoM conjugado com Análise de Conglomerado}

Como foi exposto na seção anterior, o método GoM é capaz de estimar o grau de associação de cada elemento (i) a cada perfil $(\mathrm{K})$ a partir das respostas discretas (Yijl) dadas a um leque de variáveis $(J)$. Em se tratando de, por exemplo, dois perfis, pode-se encontrar o seguinte caso: o elemento (i) pertence ao perfil (1) ou o elemento (i) pertence ao perfil (2) ou, ainda, o elemento (i) pertence a ambos. Nesse caso, ter-se-ía na realidade três perfis: dois puros e um híbrido que seria um meio termo entre as características de um e outro perfil puro. Entretanto, quando se quer relacionar os elementos (i) à mais de duas partições nebulosas (k), os elementos híbridos - isto é, os que possuem escore GoM (gik) distribuídos por vários perfis - podem ser de difícil classificação.

Há, por outro lado, vários métodos que poderiam “reclassificar" esses elementos, a partir de seus escores GoM, de modo que identificassem e agrupassem os elementos híbridos em grupos de grande similaridade interna e grande dissimilaridade externa. O que será aplicado aos escores GoM estimados a partir de variáveis selecionadas do Censo Cadernos do Leste 
Demográfico de 1991, referente às microrregiões nordestinas, é a técnica de Analise de Conglomerado, ou Análise Cluster (Aldenderfer, Blashfield, 1984).

Esse procedimento permite, através de algoritmos heurísticos, classificarelementos em relação à um conjunto de variáveis em conglomeradosnão definidos à priori mas que surgem ao longo do tratamento matemático.Em geral, esses algoritmos geram uma medida de similaridade entre os elementos,uma das mais utilizadas é a distância euclidiana entre os elementos, dispostos em um plano multidimensional. Pode-se se dizer, assim, que se tratade um procedimento estatístico multivariado que visa identificar elementoshomogêneos a partir da combinação dos valores das variáveis a eles relacionados.

\section{3- OS TIPOS PUROS}

O tipo puro número 1 caracterizou-se por apresentar percentuais das variáveis de industrialização e terciarização bem acima da mediana dos municípios mineiros. O principal aspecto dessa dimensão, para esse tipo, foi a prevalência de percentuais acima da mediana de trabalhadores de alta qualificação; e os percentuais também acima da mediana de ocupados nos setores industrial, comercial e de serviços. Em contrapartida, também se verificou os menores Percentuais de ocupados no setor agropecuário; apresentou ainda percentuais acima da mediana das variáveis de consumo, tal como percentual de domicílios com geladeira, com freezer e com aspirador de pó. Foram encontrados percentuais bem abaixo da mediana de pessoas cuja renda familiar por capta excedia a três ou mais salários mínimos e de analfabetismo e percentuais acima da mediana de pessoas acima de 15 anos com pelo menos o primeiro grau completo, de famílias compostas e estendidas.

Nesse tipo, foram encontrados tamanhos populacionais acima da mediana; apresentou também os maiores percentuais de população residindo em áreas urbanas e de população imigrante, de domicílios com luz elétrica, com água encanada internamente, com instalações sanitárias e com coleta de lixo. Em relação às característica de construção desses domicílios, pôde-se observar que também foram acima da mediana os percentuais de domicílios cujas paredes eram de alvenaria, de laje de concreto e edificados como apartamentos. Em relação às variáveis de acesso a meios de comunicação de massa o tipo puro número 1 apresentou percentuais acima da mediana de domicílios com rádio, com televisão, com telefone. Nesse tipo, foram encontrados percentuais abaixo da mediana de analfabetismo e percentuais acima da mediana, de famílias compostas e 
estendidas e de pessoas vivendo sozinhas. Dadas as conformações provenientes das variáveis que compuseram esse perfil, o tipo puro número 1 foi rotulado de Tipo Urbano Industrial Terciarizado (ÍndiceRelativo de Modernização $=8,35$ ). ${ }^{3}$

O tipo puro número 2 também se caracterizou por apresentar percentuais das variáveis de industrialização acima da mediana dos municípios, embora abaixo daqueles encontrados no tipo puro anterior. Apresentou, também, elevados percentuais das variáveis de produção e de consumo; em relação às variáveis de urbanização, esse tipo caracterizouse por apresentar elevados

percentuais das variáveis de Intensidade e de infra-estrutura urbana; e, no que tange às variáveis de desenvolvimento e acesso a meios de comunicação de massa, o tipo puro número 2 apresentou elevados percentuais de domicílios com rádio, com televisão e com telefone. Pelas conformações provenientes das variáveis acima, o tipo puro número 2 foi rotulado de Tipo UrbanoIndustria (Índice Relativo de Modernização = 6,63).

O tipo puro número 3 caracterizou-se por apresentar percentuais das variáveis de industrialização e urbanização em torno da mediana dos municípios. A partir da análise dos resultados das variáveis que compuseram esse perfil, o tipo puro número 3 foi rotulado de Tipo Rural Industrializado (Índice Relativo de Modernização = 5,71).

O tipo puro número 4 caracterizou-se por apresentar percentuais das variáveis de industrialização e urbanização abaixo da mediana dos municípios. Dadas as conformações provenientes das variáveis que compuseram esse perfil, o tipo puro número 4 foi rotulado de Tipo Rural Parcialmente Industrializado (Índice Relativo de Modernização $=4,58$ ).

O tipo puro número 5 caracterizou-se por apresentar os mais baixos percentuais das variáveis de industrialização dos municípios. Apresentou, também, os mais baixos percentuais das variáveis de produção e de consumo e o mesmo se verificou para as variáveis de urbanização, ou seja, esse tipo caracterizou-se por apresentar baixos percentuais das variáveis de Intensidade e

de infra-estrutura urbana; e, no que tange às variáveis de desenvolvimento e acesso a meios de comunicação de massa, o tipo puro número 5 apresentou baixos percentuais de domicílios com rádio, com televisão e com telefone. Assim, o tipo puro número 5 foi rotulado de Tipo Rural Tradicional (Índice Relativo de Modernização = 2,67).

\footnotetext{
${ }^{3}$ Como cada variável foi categorizada em 10 intervalos ascendentes de acordo com os decis das variávies, optou-se por calcular um índice relativo de modernização a partir da média do somatório do produto dos número inteiro correspondentes à cada categoria e seu $\lambda$ em cada variável de cada perfil, ou seja, esse índice é simplesmente a média das categorias ponderada pelos seus respectivos parâmetros. Cabe ainda ressaltar que, de acordo com os critérios para a categorização das variáveis, pode-se dizer que índices acima de 5,5 revelam prevalências acima da mediana dos municípios mineiros e índices abaixo de 5,5 revelam prevalências abaixo da mediana dos municípios de Minas Gerais.
} 
O Gráfico 1 sintetiza os resultados dos perfis puros e seus respectivos índices gerais provenientes da aplicação da técnica GoM sobre as informações das variáveis selecionadas e categorizadas dos municípios mineiros.

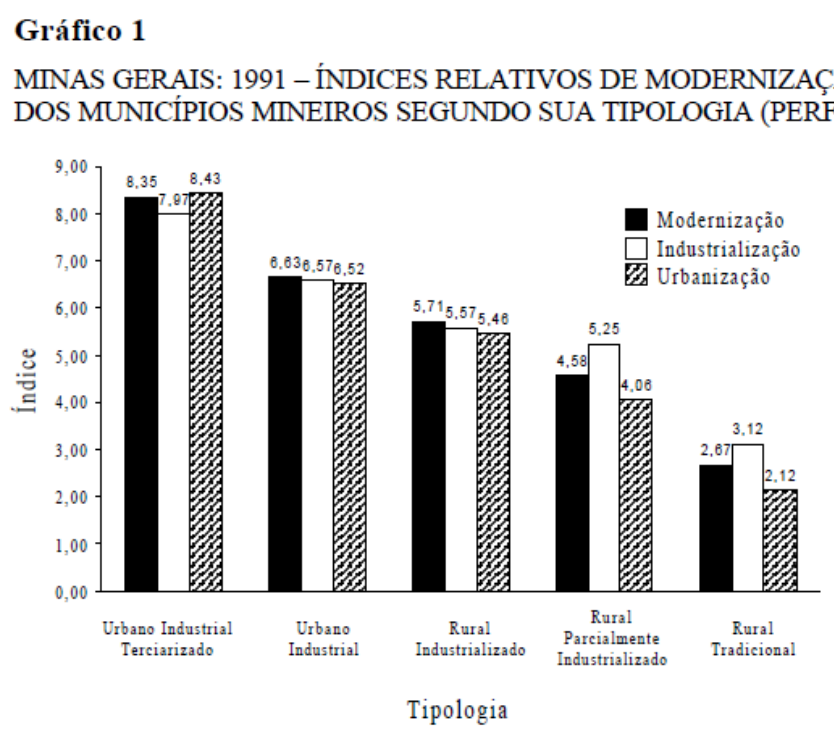

Fonte: IBGE. Censo Demográfico de 1991. (Tabulações Especiais Cedeplar/UFMG).

A partir dos parâmetros da análise de GoM ( $\square$ kjl e $\square$ gik ) dos municípios pôde-se, através da análise de conglomerado, estimar os tipos híbridos e seus respectivos índices relativos médios de modernização como já explicitado. O Gráfico 2 traz a composição média dos tipos híbridos em relação aos

tipos puros, bem como seus índices relativos de modernização. 


\section{Gráfico 2}

MINAS GERAIS: 1991

TIPOLOGIA DE MODERNIZAÇÃO E ÍNDICES RELATIVOS

DE MODERNIZAÇÃO DOS MUNICÍPIOS MINEIROS (PERFIS HÍBRIDOS)

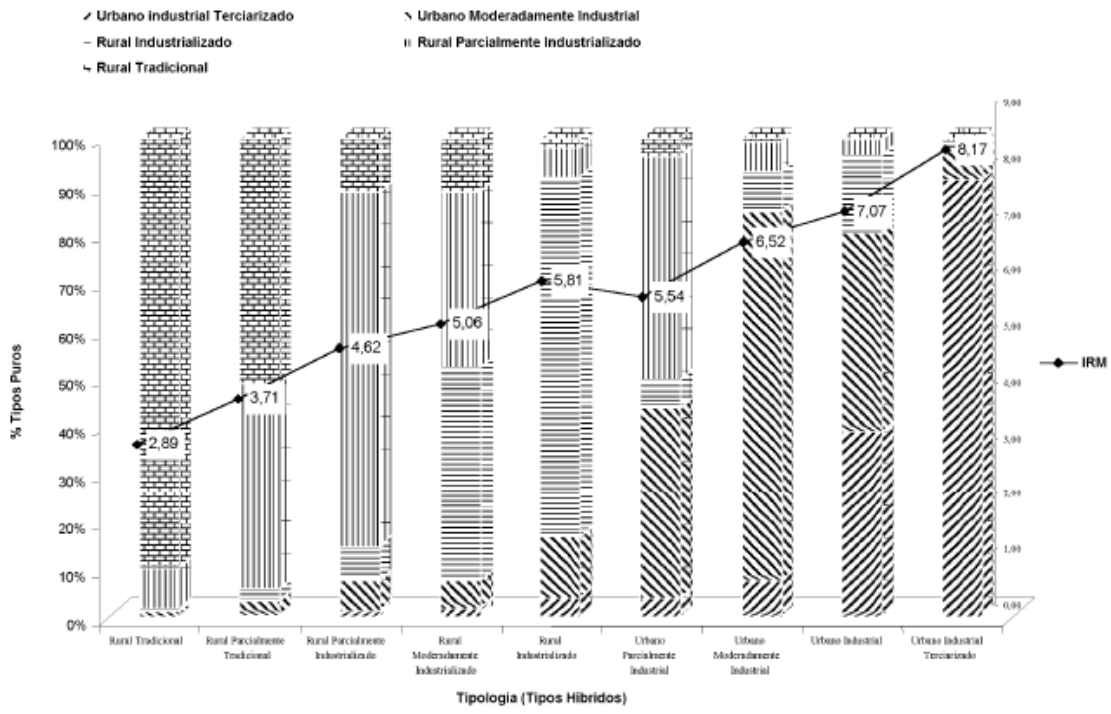

Fonte: IBGE. Censo Demográfico de 1991. (Tabulações Especiais Cedeplar/UFMG).

\section{4- MODERNIZAÇÃO E CRESCIMENTO POPULACIONAL}

Como já foi mencionado, a taxa anual de crescimento total (TCT) dos municípios, foi tratada como a variável externa do modelo GoM, assim, ela não participou na configuração dos perfis mas pôde-se verificar qual seu comportamento em relação aos cinco tipos puros propostos. O Gráfico 3 ilustra a tendência do parâmetro $\square \square$ em relação à variável TCT para cada perfil da tipologia. Grosso modo, uma tendência direta entre grau de modernização e crescimento populacional é sugerida, embora não se trate exatamente de uma relação funcional. 


\section{Gráfico 3}

MINAS GERAIS: 1991-1996

TAXA DE CRESCIMENTO TOTAL (A.A.) SEGUNDO TIPOLOGIA

DE MODERNIZAÇÃO DOS MUNICIPIOS MINEIROS (TIPOS PUROS)

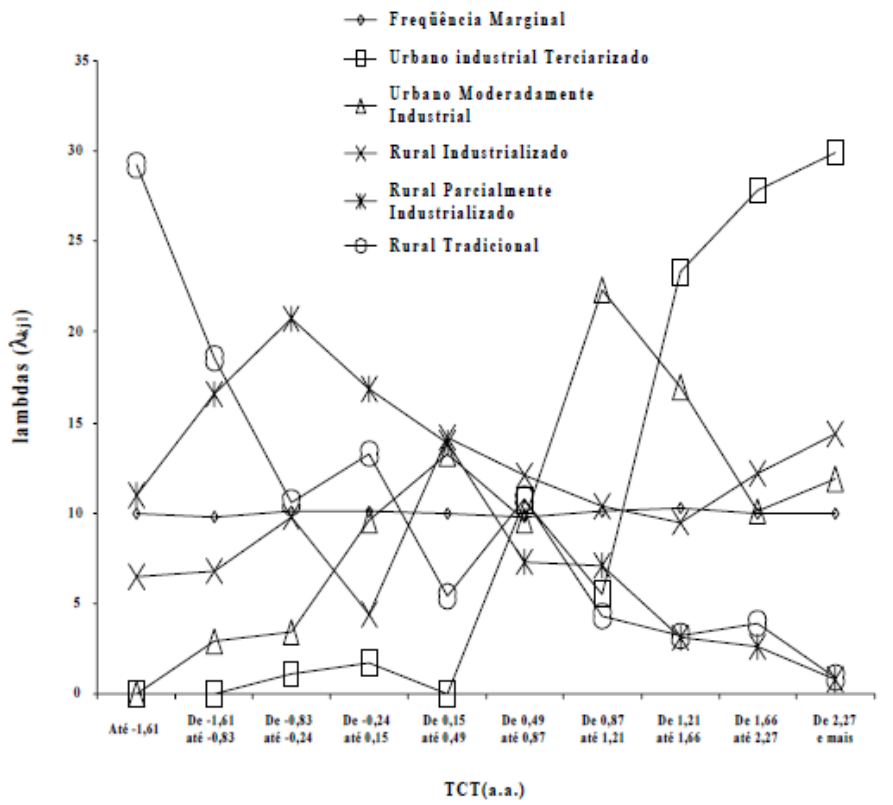

Fonte: IBGE. Censo Demográfico de 1991. (Tabulações Especiais Cedeplar/UFMG).

\section{5- DISTRIBUIÇÃO ESPACIAL DOS RESULTADOS}

A distribuição espacial das Taxas de Crescimento Total (a.a.) dos municípios mineiros pode ser observada na Figura 1. Nota-se que parece os municípios que ganharam população entre 1991 e 1996 são minoria quando comparados com aqueles que perderam ou mantiveram seu nível populacional no período.

Algo semelhante ocorre com o nível de modernização desses municípios, como era de se esperar, os maiores índices encontram-se naqueles que exercem um papel de município sede de administrações regionais e o mesmo acontece com os municípios em torno deles, embora também se verifiquem índices elevados de modernização em outras situações, principalmente na fronteira com o Estado de São Paulo, tal como pode ser observado na Figura 2. 
Figura 1

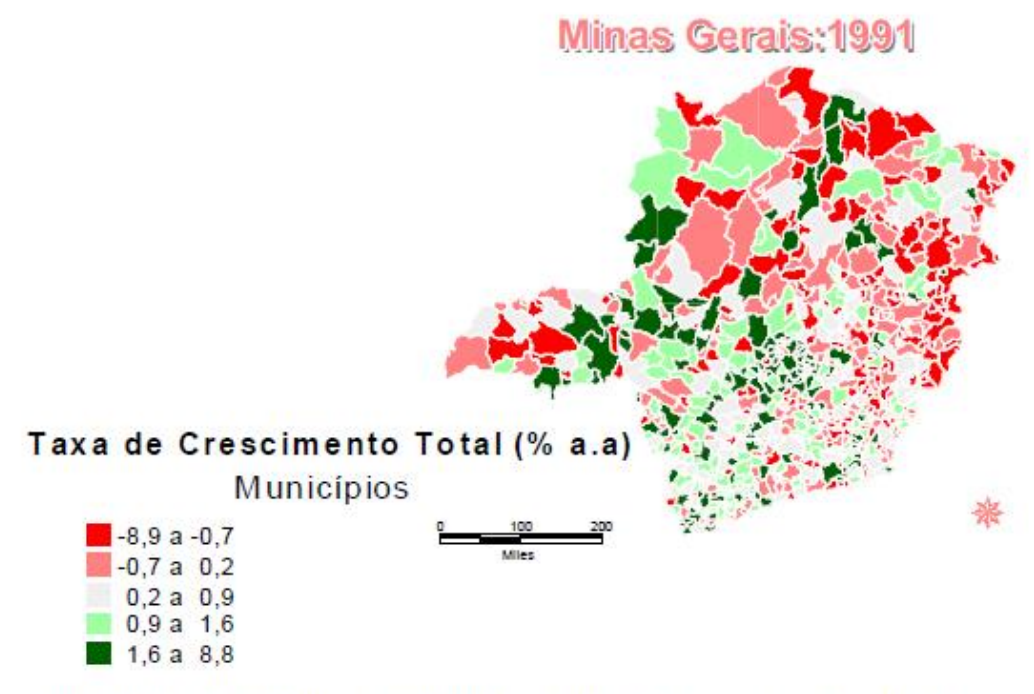

Fonte: IBGE. Censo Demográfico de 1991. (Tabulações Especiais Cedeplar/UFMG).

\section{Figura 2}

\section{Minas Gerais: 1991}

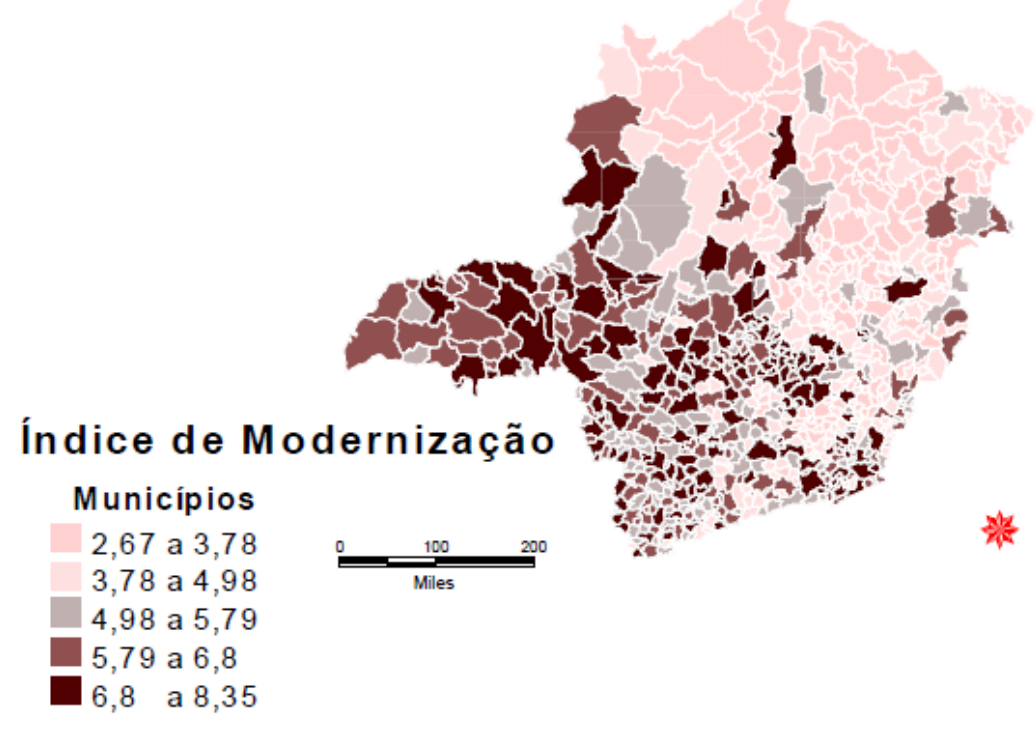

Fonte: IBGE. Censo Demográfico de 1991. (Tabulações Especiais Cedeplar/UFMG).

A Figura 3 apresenta a distribuição espacial dos perfis de modernização dos municípios mineiros. Nessa figura, pode-se perceber, nitidamente, o quão diversificada e heterogênea são essas localidades que compõem o grande Estado de Minas Gerais. 
Figura 3

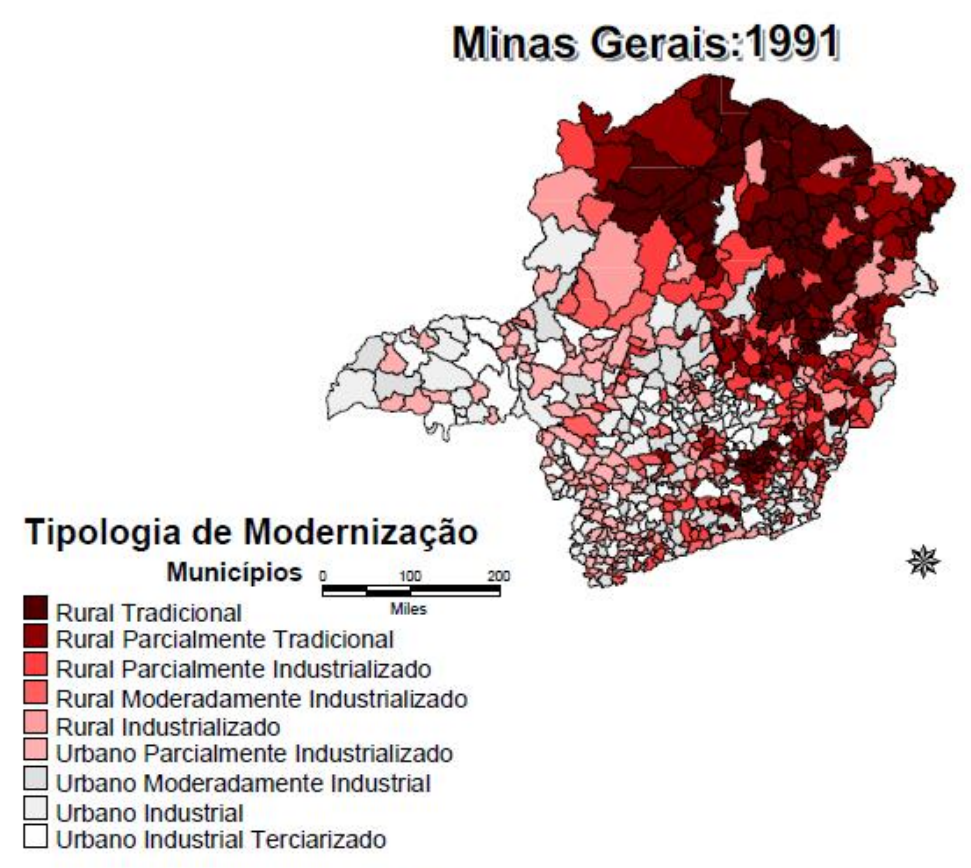

Fonte: IBGE. Censo Demográfico de 1991. (Tabulações Especiais Cedeplar/UFMG).

Por fim, a Figura 4 ilustra ainda outras informações, uma vez que conjuga a distribuição dos índices de modernização com a distribuição espacial da malha de estradas do estado. A princípio, pouco se pode dizer pois, aparentemente, Minas possui um grande e espraiado número de estradas. Ocorre que, quando se observa os municípios com elevado grau de modernização, eles estão dispostos sobre as principais rodovias do Estado. 


\section{Figura 4}
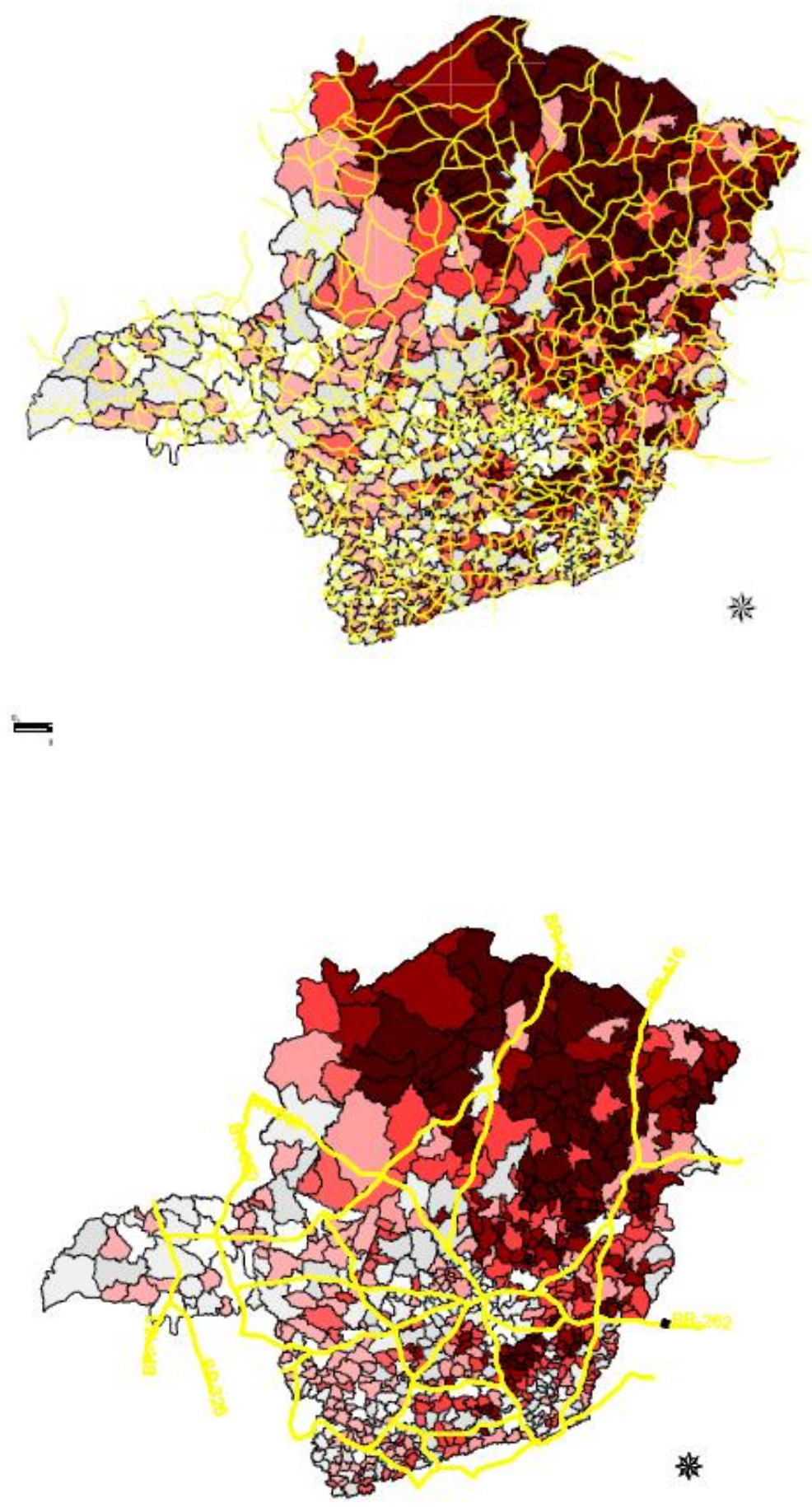

Fonte: IBGE. Censo Demográfico de 1991. (Tabulações Especiais Cedeplar/UFMG). 


\section{6- CONSIDERAÇÕES FINAIS}

Apesar de se tratar de um estudo agregado, em que se buscou evidenciar a associação entre níveis altos de crescimento populacional e níveis baixo de modernização, dada as particularidades dos fenômenos em questão e da fonte de dados escolhida, não foi possível evidenciar a variabilidade do grau de modernização em nível micro. Assim, não se poderia evitar o argumento de que, em relação à dinâmica demográfica, há a possibilidade de que níveis altos de crescimento populacional - desmembrados em seus componentes básicos: fecundidade, mortalidade e migração - prevaleçam mesmo sob condições altas de modernização socioeconômica e vice-versa. Para contornar essa questão, seria necessário o emprego de outras técnicas que permitissem identificar tanto o comportamento das determinantes demográficas quanto o grau de modernização. Acredita-se, contudo, que os elementos arrolados são suficientes para justificar a execução deste estudo. Entretanto, fica o apontamento acima como sugestão para estudos futuros.

Entretanto, alguns resultados podem contribuir para os estudos sobre o processo de transformação socioeconômica dos municípios mineiros e seus impactos na dinâmica demográfica dessas localidades. Do ponto de vista metodológico, em primeiro lugar, a técnica "Grade of Membership" associada à Análise de Conglomerado mostrou-se eficaz no trato de um grande número de variáveis, provenientes de um número relativamente pequeno de observações, na classificação dos municípios e na construção de uma medida sintética de modernização; e em segundo, o georreferenciamento das taxas de crescimento total e dos índices de modernização permitiu que se tivesse acesso à distribuição espacial desses resultados, facilitando a análise dos resultados.

Com relação ao principal objetivo desse estudo, pode-se dizer que, pelo menos em nível macro, pode-se detectar uma grande associação entre níveis altos de modernização e uma tendência a um crescimento populacional positivo, que seguem uma distribuição que é afetada geograficamente pela existência de estradas amplamente utilizadas como as principais vias de transporte entre os municípios mineiros e os outros estados da federação.

Assim, mesmo se tratando de uma análise cross-section de processos multideterminados, como é o caso do crescimento populacional e da modernização das sociedades mineiras, o quadro que se procurou pintar, a partir das informações disponíveis, permitiu que se conhecesse, ao menos em parte, um pouco mais sobre a realidade mineira. 


\section{REFERÊNCIAS BIBLIOGRÁFICAS}

ALDENDERFER, Mark S., BLASHFIELD, Roger K. Cluster Analysis. 3.ed. Beverly Hills: SAGE Publications, 1984.

FEATHERSTONE, M. Cultura de Consumo e Pós-Modernismo. São Paulo: Studio Nobel, 1995.

GERMANI, G. Sociologia de la modernización. Buenos Aires: Paidos, 1969.

HARVEY, D. Condição Pós-Moderna. São Paulo: Loyola, 1989.

HOLANDA, A. B. Aurélio Eletrônico, v 2.0. Rio de Janeiro: Nova Fronteira, 1996.

INGLEHART. R. Modernizatio and Postmodernization: cultural, economic, and political change in 43 societies. Princeton: Princeton University Press, 1997.

INKELES, A., SMITH, D. Tornando-se Moderno. Brasília: Universidade de Brasília, 1981.

LESTHAEGHE, R. A Century of Demographic and Cultural Change in Western Europe: An Exploration of Underlying Dimension. Population and DevelopmentReview, v. 9, n. 3, p. $411-535,1983$.

Imre Lakatos' views on theory development: applications to the field of fertility theories. Brussels: Vrije Universiteit, 1997. (IPD-Working Papers 91-91).

MACHADO, C. J. Perfis de Morbi-mortalidade Infantil no Estado de São Paulo, 1994: Uma aplicação de Grade of Membership à Análise de CausasMúltiplas de Morte. Belo Horizonte: CEDEPLAR/UFMG, 1997. (Dissertação).

MANTON, K., WOODBURY, M., TOLLEY, D. Statistical aplications using fuzzy sets. Wiley, 1994.

OLIVEIRA, V. B., WONG L. R. A queda da fecundidade nas Minas Gerais 1980/95. In: SEMINÁRIO DE ECONOMIA MINEIRA, 7, 1998, Diamantina. Anais... Belo Horizonte: CEDEPLAR/UFMG, 1998.

SAWYER, D. O., BELTRÃO, K. I. "Healthy Households" and Child Survival in Brazil. In: DEMOGRAPHICS AND HEALTH SURVEYS WORLD CONFERENCE, 1991, Washington. Proceedings... Columbia: IRD/Macro International, Inc., 1991. p. 205-222.

CASTILHA, R. F., MONTE-MOR, R. The impact of urbanization and industrialization mortality in Brazil. World Helth Statistic, v 40, p 84-96, 1987.

ZADEH, L. A. Fuzzy sets. Inf. Control, v. 8, p. 338-353, 1965. 